\title{
Removal of Heavy Metal Cations (Copper, Lead, Zinc) from Water Runoff by Calcium Silicate Hydrate: Effect of the Co-Ion and Competition of Ions in Ternary Mixtures
}

\author{
M Brogat, S Pontvianne, L Sigot and C Vallières* \\ Laboratoire Réactions et Génie des Procédés, Université de Lorraine, CNRS, LRGP, F-54000 Nancy, France
}

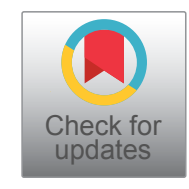

\begin{abstract}
The sorption behavior of calcium silicate hydrate (CSH) with respect to lead, copper and zinc was studied to consider its application to remove metal from water runoff. A series of kinetics of removal and isotherms were undertaken with single metal and mixture solutions. The sorption occurred by ion exchange with calcium. Sorption kinetics were modelled using pseudo-second order model. The weight capacities of CSH were lead > copper > zinc when studied separately. The co-ion associated to the metal ion is of importance on the removal capacities. Langmuir-Freundlich isotherm model matched experimental data in the case of single metal solutions. A competition was evidenced in mixture; zinc was the most impacted.
\end{abstract}

Keywords

Surface water runoff treatment, Heavy metal removal, Calcium silicate hydrate, Cation exchange, Sorption kinetics and isotherms

\section{Highlights}

- Performances of calcium silicate hydrate (CSH) to capture metal ions are evaluated

- Retention capacitiesin $\mathrm{mg}_{\mathrm{metal}} \cdot \mathrm{g}_{\mathrm{CSH}}{ }^{-1}$ follows the order $\mathrm{Pb}(\mathrm{II})$ $>\mathrm{Cu}(\mathrm{II})>>\mathrm{Zn}(\mathrm{II})$

- Removal kinetics and isotherms are properly modeled by pseudo-second order model and Langmuir-Freundlich model respectively

- The co-ion associated to the metal is of importance on the removal capacity

- Retention capacities for $\mathrm{Cu}, \mathrm{Pb}$ and $\mathrm{Zn}$ decrease in the case of a ternary metal mixture

\section{Introduction}

Water pollution caused by organic and inorganic compounds is a world issue originated by natural and anthropogenic sources. Experience with metals showed that they can give rise to specific concerns due to their potential to accumulate in parts of the environment and their potential toxic effects on animals, plants and humans [1]. Some of them are even now included in the list of priority pollutants:

\footnotetext{
Four heavy metals (cadmium, lead, mercury and nickel)in the list of priority pollutants of the European Union Water Framework Directive 2000/60/Ec [2]
}

- Thirteen heavy metals (antimony, arsenic, beryllium, cadmium, chromium, copper, lead, mercury, nickel, selenium, silver, thallium and zinc) in the list of priority pollutants of the US Environmental Protection Agency (EPA) [3].

Even if all of heavy metals are present in the Earth crust, their wide presence in waters, soils and atmosphere is mainly due to human activities (industries, car traffic, urbanization,...) and can affect the quality and ecology of receiving waters [46]. Storm water runoff has been identified as a main cause of pollutant diffusion in the environment [7-9]. For example, motor vehicle emissions and vehicle tire wears are some of diffuse sources of chemical contaminants in urban environments [10]. During rainfalls, these chemical contaminants are washed out from different surfaces such as roofs and roads

*Corresponding author: C Vallières, Laboratoire Réactions et Génie des Procédés, Université de Lorraine, CNRS, LRGP, F-54000 Nancy, France, Tel: +33-3-72-74-37-32

Accepted: May 12, 2021

Published online: May 14, 2021

Citation: Brogat M, Pontvianne S, Sigot L, Vallières C (2021) Removal of Heavy Metal Cations (Copper, Lead, Zinc) from Water Runoff by Calcium Silicate Hydrate: Effect of the Co-Ion and Competition of Ions in Ternary Mixtures. Adv Environ Stud 5(1):404-415 
Citation: Brogat M, Pontvianne S, Sigot L, Vallières C (2021) Removal of Heavy Metal Cations (Copper, Lead, Zinc) from Water Runoff by Calcium Silicate Hydrate: Effect of the Co-Ion and Competition of Ions in Ternary Mixtures. Adv Environ Stud 5(1):404-415

Table 1: CSH elemental analysis.

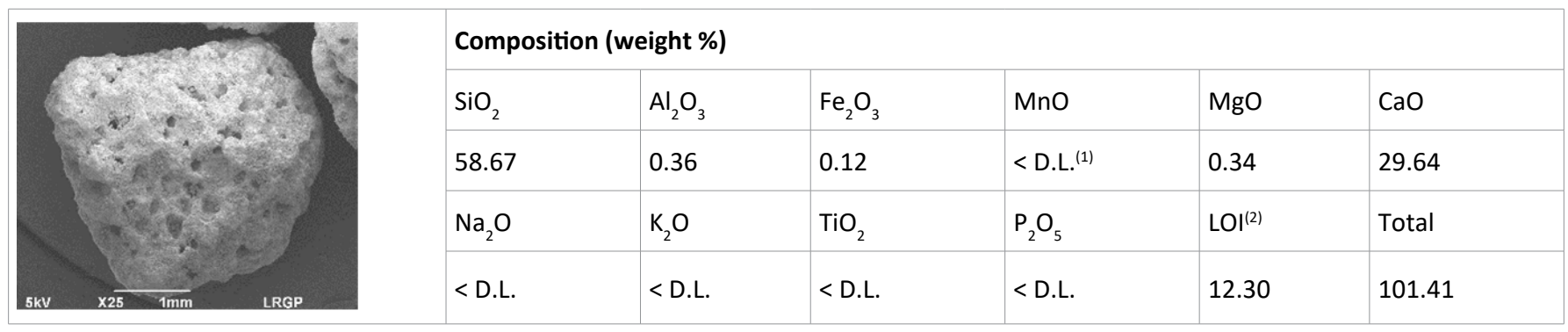

(1) < D.L.: Below the detection limit; (2) LOI: Loss of ignition at $1000^{\circ} \mathrm{C}$.

into the stormwater system $[7,10]$. Heavy metals such as copper $(\mathrm{Cu}(\mathrm{II}))$, lead $(\mathrm{Pb}(\mathrm{II}))$ and zinc $(\mathrm{Zn}(\mathrm{II}))$ are of particular concern in such runoff due to their occurrence, toxicity to aquatic organisms and persistence in the environment $[5,11,12]$.

To remove heavy metal ions from water, several processes exist such as sorption [13-15], phytoextraction [1,16,17], ultrafiltration [18,19] and reverse osmosis [20]. Sorption techniques are often used due to their simplicity as well as the availability of a wide range of sorbents [21]. Materials such as activated carbons, zeolites and calcium silicate hydrates (CSH) have been used to remove heavy metals from water [14,22-26]

According to Zhao, et al. [24], CSH received attention by means of their excellent bioactivity and biocompatibility. Some studies were carried out to explore their applications in drug delivery and sorption of heavy metal ions. Chen, et al. [25] showed that this low-cost material is a promising sorbent for $\mathrm{Pb}(\mathrm{II}), \mathrm{Cu}(\mathrm{II}), \mathrm{Zn}(\mathrm{II})$ and $\mathrm{Cr}(\mathrm{III})$ ion removal from aqueous solutions with sorption capacities between 31 and $94 \mathrm{mg}_{\text {Metal }}$. $\mathrm{g}_{\mathrm{CSH}}{ }^{-1}$. Ma, et al. [26] studied the capture of $\mathrm{Ni}(\mathrm{II}), \mathrm{Cu}(\mathrm{II}), \mathrm{Zn}(\mathrm{II})$ and $\mathrm{Co}(\mathrm{II})$ ions from aqueous solutions and showed the potentiality of a $\mathrm{CSH}$, by-product of alumina production. The announced capacities reached values between 240 and 700 $\mathrm{mg}_{\text {Metal }} \cdot \mathrm{g}_{\mathrm{CSH}}{ }^{-1}$.

In this paper, the performance of one kind of CSH for the removal of three heavy metals (copper, lead and zinc) was evaluated when present alone but also in mixture in water. Among the objectives, a special focus was addressed to the comprehension of the retention mechanisms, the analysis of competition phenomena, and the influence of the nature the co-ions present in solution. This experimental study, based on kinetics and thermodynamics approaches, is the first step in the conception and development of an innovative in-situ treatment solution integrated into the water runoff management system.

\section{Materials and Methods \\ Characterization of the CSH}

The studied calcium silicate hydrate (CSH) is a commercial $\sim 3 \mathrm{~mm}$-granular CSH with a $\mathrm{Ca} / \mathrm{Si}$ ratio equal to 0.77 (Table 1) and used as received. CSH samples were characterized (before and after metal sorption) by Scanning Electron Microscopy (SEM; JEOL JSM-6490LV, Jeol, Japan) coupled to a module of Energy Dispersive X-ray Spectrometry (EDX) (NumeriX DXP-
X10P digital X-ray processor, SamX, France). The preparation of each sample was based on the fixation of an Au-Pd thin layer using an ion sputter (Fine Coat lon Sputter JFC-1100, Jeol, Japan). Observations of the samples were conducted using 5 $\mathrm{kV}$ of accelerating voltage. The EDX analyses were conducted with $20 \mathrm{kV}$ accelerating voltage.

The elemental composition of ground samples $(<80 \mu \mathrm{m})$ was analyzed by ICP-OES (inductively coupled plasma - optical emission spectrometry) after alkaline fusion and acidic dissolution by the SARM analytical research facility (CRPG, CNRS, Nancy). Weight percent compositions were expressed as oxidized form (Table 1). The loss on ignition at $1000^{\circ} \mathrm{C}$ (corresponding mainly to organic matter, carbonates and water) was also given. A textural analysis by nitrogen adsorption at $77 \mathrm{~K}$ (Tristar II, Micromeritics) revealed that the CSH material is not microporous.

\section{Reagents}

The studied metal ions were $\mathrm{Cu}(\mathrm{II}), \mathrm{Zn}(\mathrm{II})$ and $\mathrm{Pb}(\mathrm{II})$. All compounds were analytical-grade reagents with purity higher than $98 \%$. Synthetic solutions of $\mathrm{Cu}(\mathrm{II}), \mathrm{Zn}(\mathrm{II})$ and $\mathrm{Pb}$ (II) were prepared using nitrate salts or sulfate salts in ultrapure water. $\mathrm{Cu}\left(\mathrm{NO}_{3}\right)_{2}, 3 \mathrm{H}_{2} \mathrm{O}, \mathrm{Zn}\left(\mathrm{NO}_{3}\right)_{2}, 6 \mathrm{H}_{2} \mathrm{O}$ were supplied by Acros Organic (USA) and $\mathrm{Pb}\left(\mathrm{NO}_{3}\right)_{2}, \mathrm{CuSO}_{4}, 5 \mathrm{H}_{2} \mathrm{O}$ and $\mathrm{ZnSO}_{4}, 7 \mathrm{H}_{2} \mathrm{O}$ were supplied by VWR BDH Prolabo (UK). Nitric acid was used to acidify the samples before analysis by ICP-OES. Nitric acid (67$70 \%$ ) of ICP-OES quality was purchased from Fisher Scientific (USA).

\section{Batch sorption studies}

In order to simplify the notations, all masses, volumes, concentrations and sorption capacities will always refer to a metal mass in milligram, a solution volume in liter (or $\mathrm{mL}$ ) and a CSH mass in gram.

Kinetics experiments: Solutions containing metal ions at $3000 \mathrm{mg} \cdot \mathrm{L}^{-1}$ were prepared. Batch sorption kinetics experiments were conducted at $22{ }^{\circ} \mathrm{C}$ by contacting $200 \mathrm{~mL}$ of solution with a known amount of CSH in 240-mL LDPE bottles. The bottles were shaken in an orbital shaker (STARLAB). Aqueous samples were taken at different time intervals until the equilibrium was reached. Aqueous samples were filtered through a $0.45 \mu \mathrm{m}$ nylon filter (VWR, UK), diluted if necessary with ultrapure water and then acidified to $2 \%$ with $\mathrm{HNO}_{3}$ for analysis by ICP-OES (ICAP 6300 DUO, Thermo Scientific, USA). Absorption wavelengths used were $224.7 \mathrm{~nm}$ for $\mathrm{Cu}$ (II), 202.5 


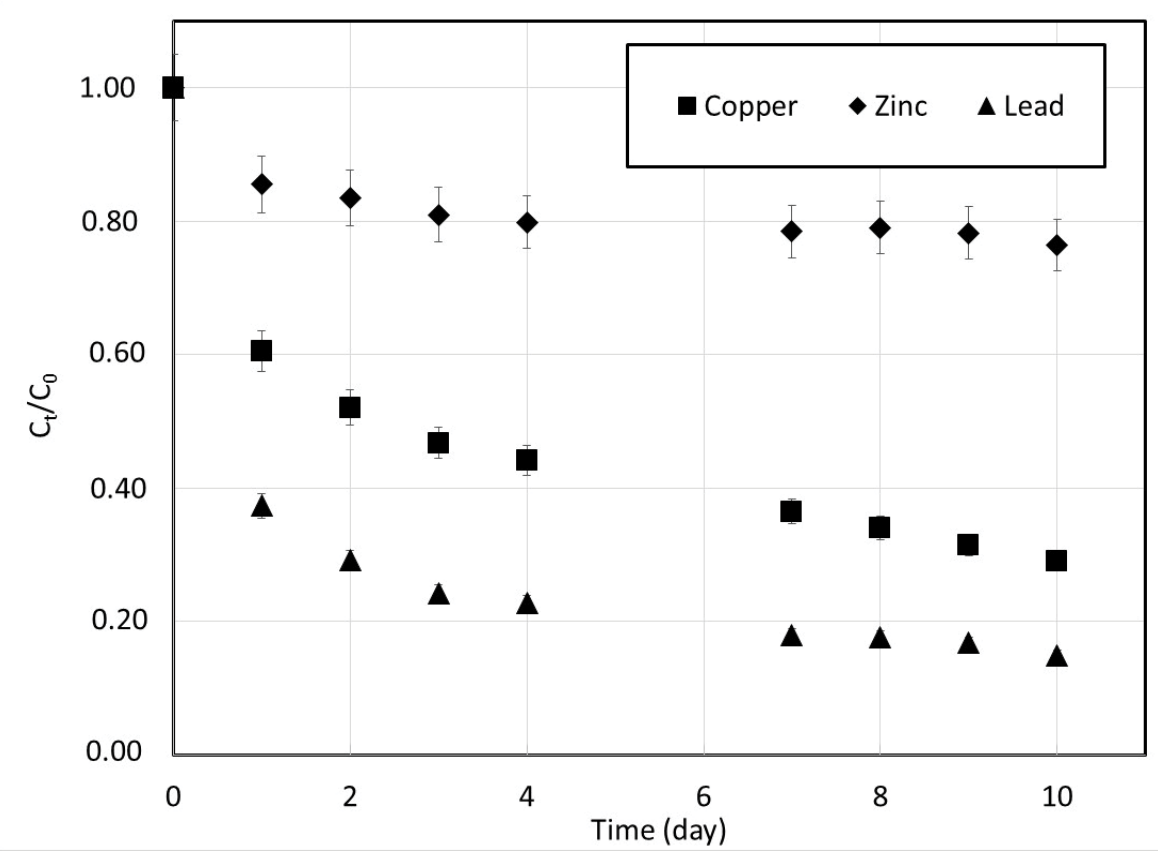

Figure 1: Long-term kinetics for copper, lead and zinc removal from single metal solutions containing nitrates using $\mathrm{CSH}\left(\mathrm{T}=22^{\circ} \mathrm{C}, \mathrm{C}_{0}\right.$ $\left.=3000 \mathrm{mg} \cdot \mathrm{L}^{-1}, \mathrm{~V}=200 \mathrm{~mL}, \mathrm{~m}_{\mathrm{CSH}}=2.5 \mathrm{~g}\right)$.

$\mathrm{nm}$ for $\mathrm{Zn}(\mathrm{II})$ and $220.3 \mathrm{~nm}$ for $\mathrm{Pb}(\mathrm{II})$.

Sorption isotherms: The sorption isotherms of heavy metals on CSH were carried out using the batch method to evaluate the equilibrium capacities of the material. Isotherms at $22{ }^{\circ} \mathrm{C}$ were obtained by contacting $200 \mathrm{~mL}$ of heavy metal ion solution (3000 mg. $\mathrm{L}^{-1}$ ) with various masses of $\mathrm{CSH}$ ranging from $0.5 \mathrm{~g}$ to $40 \mathrm{~g}$ in 240-mL LDPE bottles. The bottles were shaken in an orbital shaker (STARLAB) until the equilibrium was attained. Finally, a $10 \mathrm{~mL}$ supernatant liquid volume of each sample was filtered, diluted if necessary, acidified and analyzed by ICP-OES as described in the previous paragraph.

The amount of metal retained was calculated by:

$$
q_{t}=\frac{\left(C_{0}-C_{t}\right) \cdot v}{m_{C H S}}
$$

where $q_{t}$ is the amount of metal retained at time $t$ (mg.g $\left.{ }^{1}\right), C_{0}$ is the metal initial concentration in solution $\left(\mathrm{mg} \cdot \mathrm{L}^{-1}\right), C_{t}$ is the metal concentration in solution at time $t\left(\mathrm{mg} \cdot \mathrm{L}^{-1}\right), V$ is the volume of the solution (L) and $m_{\mathrm{CSH}}$ is the mass of CSH used (g). This capacity can be calculated when the equilibrium is reached and will be noted $q_{\mathrm{e}}$.

Most of experiments were carried out twice to check the reproducibility of the results. CSH-free blanks and metal-free blanks were used as controls. Based on the replicates, the maximum error on the capacities was estimated to $\pm 10 \%$.

\section{Results and Discussion}

\section{Single metal solutions from nitrate salts}

Kinetics experiments: Kinetics measurements were conducted by following the decrease of the metal concentration in the liquid phase (Figure 1). The measurements were carried on for a long time (ten days) with rather small amounts of $\mathrm{CSH}$ ( $2.5 \mathrm{~g}$ ). As expected for liquid, the sorption rate for each metal, represented by the slope of the curves, is very high during the first hours and slowly decreases to almost zero after a contact time of several days. Gupta and Balomajumder [27] and Ullah, et al. [28] reported the same trends in their studies. This characteristic is probably due to the large availability of sorption sites on the surface of the CSH whereas sites located inside the particle are much less accessible due to the low grain porosity.

Despite the same experimental conditions used, the sorption capacities were different according to the metal retained. After ten days, $85 \%, 71 \%$ and $24 \%$ of $\mathrm{Pb}(\mathrm{II}), \mathrm{Cu}(\mathrm{II})$ and $\mathrm{Zn}$ (II) were respectively retained by the $\mathrm{CSH}$. It can be assumed that after ten days the equilibrium was reached for all metals.

The concentration of calcium ions in solution was also measured during the experiments. Figure 2 shows the amount $\left(q_{t}\right)$ in mmol.g-1 of copper, lead and zinc retained on the $\mathrm{CSH}$ and the corresponding amount of calcium released in the solutions during the kinetics experiments. Because the studied metals as well as calcium have a valence of 2 , the amounts in mmoles are also the amounts in charge. $\mathrm{Cu}(\mathrm{II}), \mathrm{Pb}(\mathrm{II})$ and $\mathrm{Zn}$ (II) uptakes perfectly match $\mathrm{Ca}$ (II) release in the solutions leading to the conclusion that ion exchange is the main mechanism involved in metal uptake by $\mathrm{CSH}$. This exchange can be represented by the following reaction:

$$
\mathrm{R}-\mathrm{Ca}+\mathrm{M}^{2+} \rightarrow \mathrm{R}-\mathrm{M}+\mathrm{Ca}^{2+}
$$

with $\mathrm{R}$, the $\mathrm{CSH}$ skeleton and $\mathrm{M}$, the metal that is $\mathrm{Cu}, \mathrm{Pb}$ or Zn.

This mechanism can also explain the slow kinetics ob- 
Citation: Brogat M, Pontvianne S, Sigot L, Vallières C (2021) Removal of Heavy Metal Cations (Copper, Lead, Zinc) from Water Runoff by Calcium Silicate Hydrate: Effect of the Co-Ion and Competition of lons in Ternary Mixtures. Adv Environ Stud 5(1):404-415
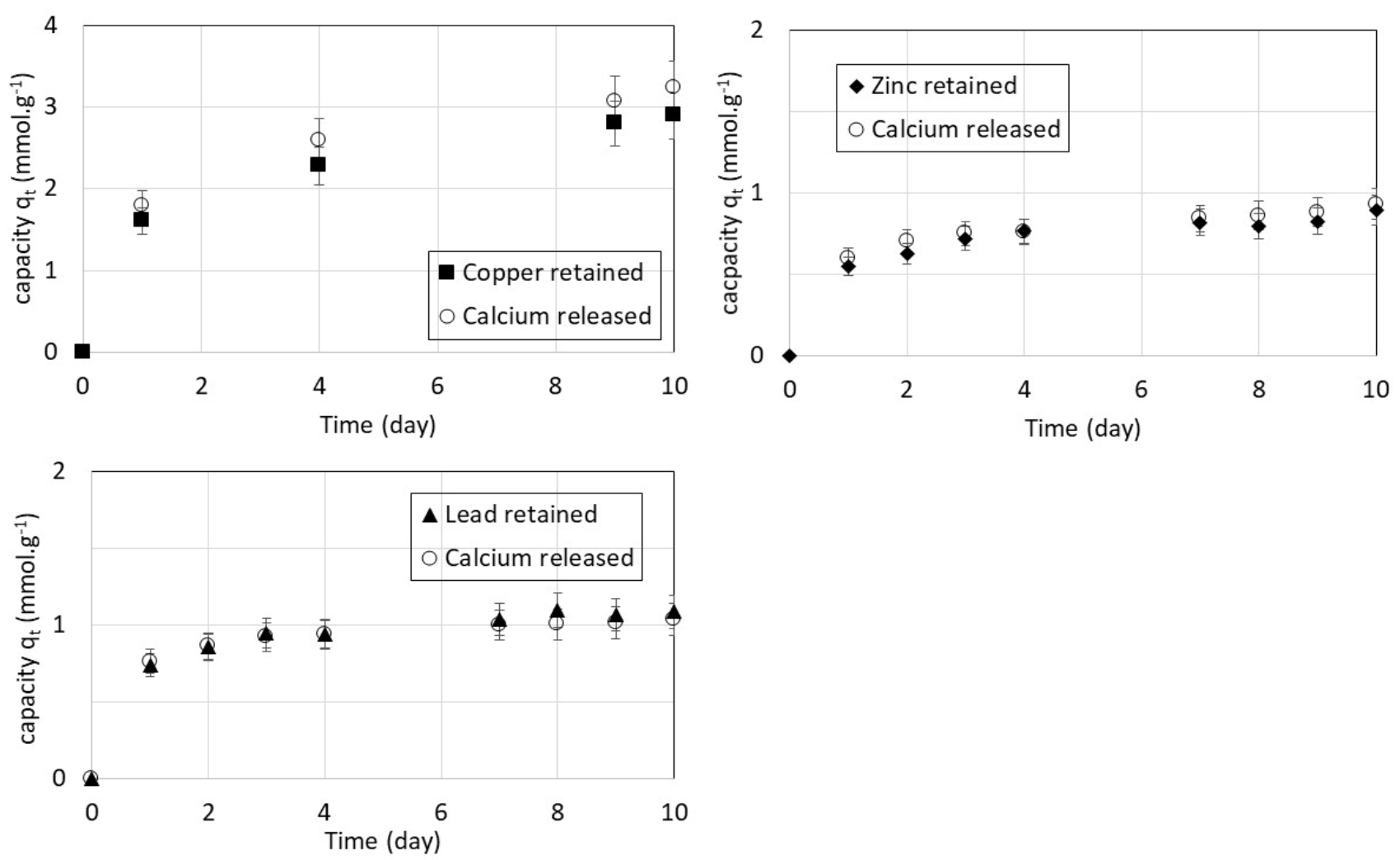

Figure 2: Amount of copper, lead and zinc retained by $\mathrm{CSH}$ and amount of calcium released from $\mathrm{CSH}\left(\mathrm{T}=22^{\circ} \mathrm{C}, \mathrm{C}_{0}=3000 \mathrm{mg} \cdot \mathrm{L}^{-1}, \mathrm{~V}=\right.$ $\left.200 \mathrm{~mL}, \mathrm{~m}_{\mathrm{CSH}}=2.5 \mathrm{~g}\right)$.

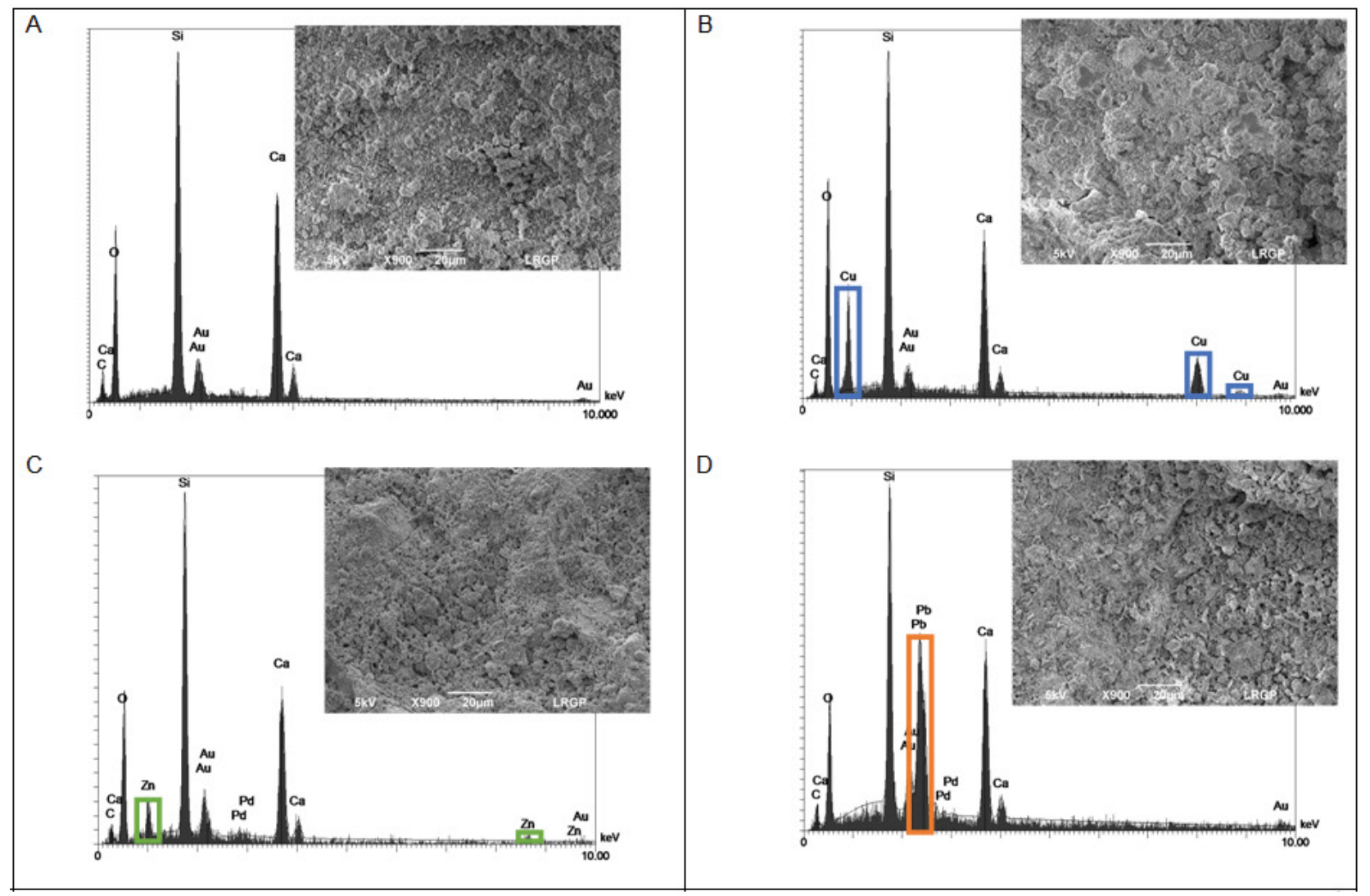

Figure 3: Amount of copper, lead and zinc retained by $\mathrm{CSH}$ and amount of calcium released from $\mathrm{CSH}\left(\mathrm{T}=22^{\circ} \mathrm{C}, \mathrm{C}_{0}=3000 \mathrm{mg} \cdot \mathrm{L}^{-1}, \mathrm{~V}=\right.$ $200 \mathrm{~mL}, \mathrm{~m}_{\mathrm{CSH}}=2.5 \mathrm{~g}$ ). 
Citation: Brogat M, Pontvianne S, Sigot L, Vallières C (2021) Removal of Heavy Metal Cations (Copper, Lead, Zinc) from Water Runoff by Calcium Silicate Hydrate: Effect of the Co-Ion and Competition of Ions in Ternary Mixtures. Adv Environ Stud 5(1):404-415

served on Figure 1. The water must enter the grain to ionize calcium before ion exchange can take place. This phenomenon, well known for ion exchange resins, probably induces some modifications of the structure of CSH such as swelling and bursting of grains.

Moreover, SEM micrographs and EDX spectra of CSH material were obtained before and after sorption of $\mathrm{Cu}(\mathrm{II}), \mathrm{Zn}(\mathrm{II})$ and $\mathrm{Pb}$ (II) (Figure 3). The apparition of additional peaks on EDX spectra after metal sorption (pictures B, C and D) confirms the presence of copper, zinc and lead at the CSH surface. The intensity of Ca peak tends to decrease after metal sorption. SEM pictures also suggest a textural modification of the $\mathrm{CSH}$ surface after metal sorption. Some agglomerates quite homogenously distributed appeared on the surface. Their typical shape seems to depend on the sorbate: Rather a smooth continuum for $\mathrm{Cu}$ or some granular growths for $\mathrm{Pb}$ and $\mathrm{Zn}$.

In order to represent the experimental data, two wellknown kinetics models (pseudo-first and pseudo-second order kinetics) based on chemical reaction process [29] and not specific to ion exchange complex process were used. For both models, the main hypotheses are that only one ion species (i.e. calcium) is exchanged with the metal, the CSH material is homogeneous and no swelling of the solid is considered.

The pseudo-first order model based on the solid capacity to sorb is expressed as:

$$
\frac{d q_{t}}{d t}=k_{1}\left(q_{e}-q_{t}\right)
$$

Where $k_{1}$ is the rate constant of pseudo-first order (day $\left.{ }^{1}\right), q_{\mathrm{e}}$ and $q_{\mathrm{t}}$ are respectively the metal amounts retained at equilibrium and at time $t$ (day) both expressed in $\mathrm{mg} \cdot \mathrm{g}^{-1}$. The resolution of equation 3 leads to:

$$
q_{t}=q_{e}\left(1-e^{-k_{1} t}\right)
$$

The pseudo-second order kinetics model based on sorption equilibrium capacity is expressed by the following equation:

$$
\frac{d q_{t}}{d t}=k_{2}\left(q_{e}-q_{t}\right)^{2}
$$

Where $k_{2}$ is the rate constant of pseudo-second order sorption (g.mg ${ }^{-1}$.day $\left.{ }^{-1}\right), q_{e}$ and $q_{t}$ are the amounts of metal retained $\left(\mathrm{mg}^{-1} \mathrm{~g}^{-1}\right)$ at equilibrium and at time $t$ (day), respectively. The resolution of equation 5 results in:

$$
q_{t}=q_{e}-\frac{1}{\frac{1}{q_{e}}+k_{2} t}
$$

The model parameters were estimated by nonlinear regression using Excel solver based on the minimization of the root mean square error (RMSE) between experimental and modeled data. A combination of absolute error measurement via the RMSE and relative error measurement via the determination coefficient $R^{2}$ was used to evaluate the goodnessof-fit.

The obtained parameters for both models are listed in Table 2. As shown in Figure 4, both models allowed to represent experimental data but the RMSE (Table 2) for the pseudo-first

\begin{tabular}{|c|c|c|c|}
\hline Pseudo-first order model & $\mathrm{Cu}$ (II) & Zn (II) & $\mathrm{Pb}$ (II) \\
\hline$k_{1}\left(\right.$ day $\left.^{-1}\right)$ & 0.67 & 0.88 & 1.32 \\
\hline$q_{\mathrm{e}}\left(\mathrm{mg} \cdot \mathrm{g}^{-1}\right)$ & 171 & 53 & 205 \\
\hline RMSE (mg.g $\left.{ }^{-1}\right)$ & 10.11 & 2.76 & 7.54 \\
\hline $\mathrm{R}^{2}$ & 0.959 & 0.972 & 0.986 \\
\hline Pseudo-second order model & $\mathrm{Cu}(\mathrm{II})$ & $\mathrm{Zn}(\mathrm{II})$ & $\mathrm{Pb}(\mathrm{II})$ \\
\hline$k_{2}\left(\mathrm{~g} \cdot \mathrm{mg}^{-1} \mathrm{day}^{-1}\right)$ & 0.0047 & 0.023 & 0.011 \\
\hline$q_{e}\left(\mathrm{mg} \cdot \mathrm{g}^{-1}\right)$ & 195 & 59 & 220 \\
\hline RMSE (mg.g $\left.\mathrm{g}^{-1}\right)$ & 5.58 & 1.65 & 2.43 \\
\hline $\mathrm{R}^{2}$ & 0.987 & 0.991 & 0.998 \\
\hline
\end{tabular}

Table 2: Kinetics parameters of the pseudo-first order and pseudosecond order kinetics models for the sorption of $\mathrm{Cu}(\mathrm{II}), \mathrm{Zn}(\mathrm{II})$ and $\mathrm{Pb}$ (II) on CSH ( $\left.\mathrm{T}=22^{\circ} \mathrm{C}, \mathrm{C}_{0}=3000 \mathrm{mg} \cdot \mathrm{L}^{-1}, \mathrm{~V}=200 \mathrm{~mL}, \mathrm{~m}_{\mathrm{CSH}}=2.5 \mathrm{~g}\right)$.
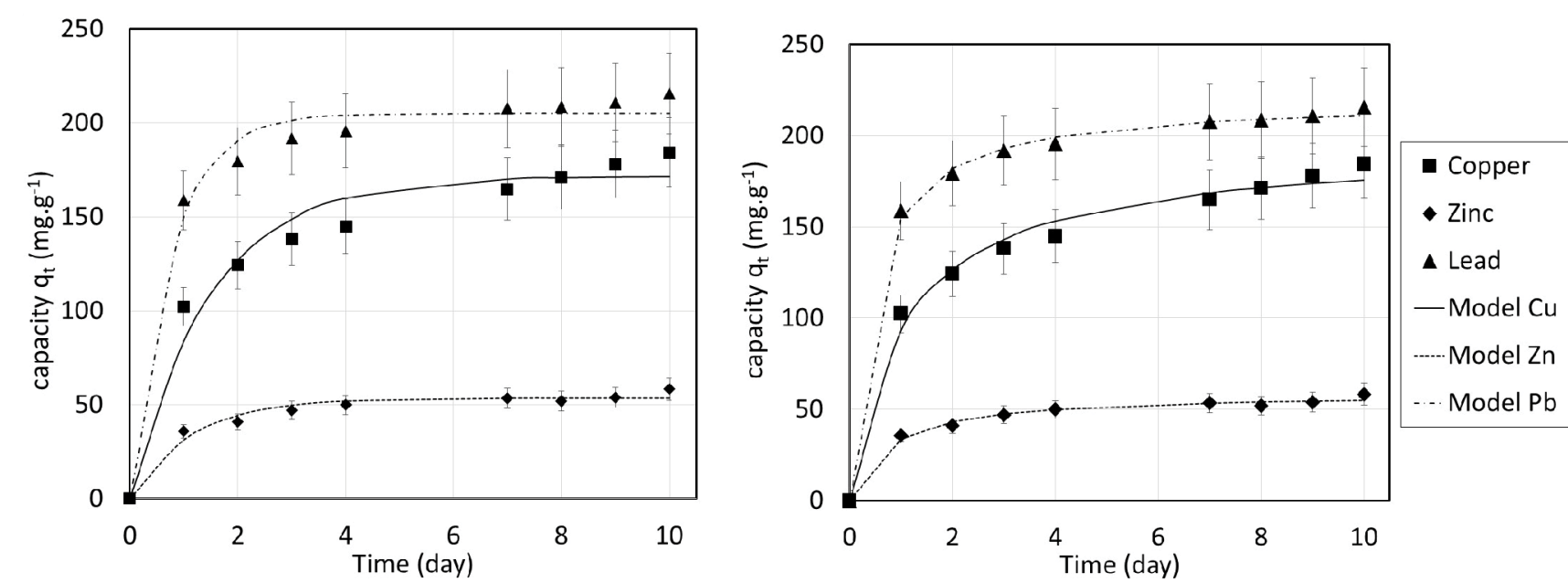

Figure 4: Comparison of experimental and modeled kinetics with pseudo-first order (left) and pseudo-second order models (right) ( $\mathrm{T}=$ $22^{\circ} \mathrm{C}, \mathrm{C}_{0}=3000 \mathrm{mg} \cdot \mathrm{L}^{-1}, \mathrm{~V}=200 \mathrm{~mL}, \mathrm{~m}_{\mathrm{CSH}}=2.5 \mathrm{~g}$ ). 


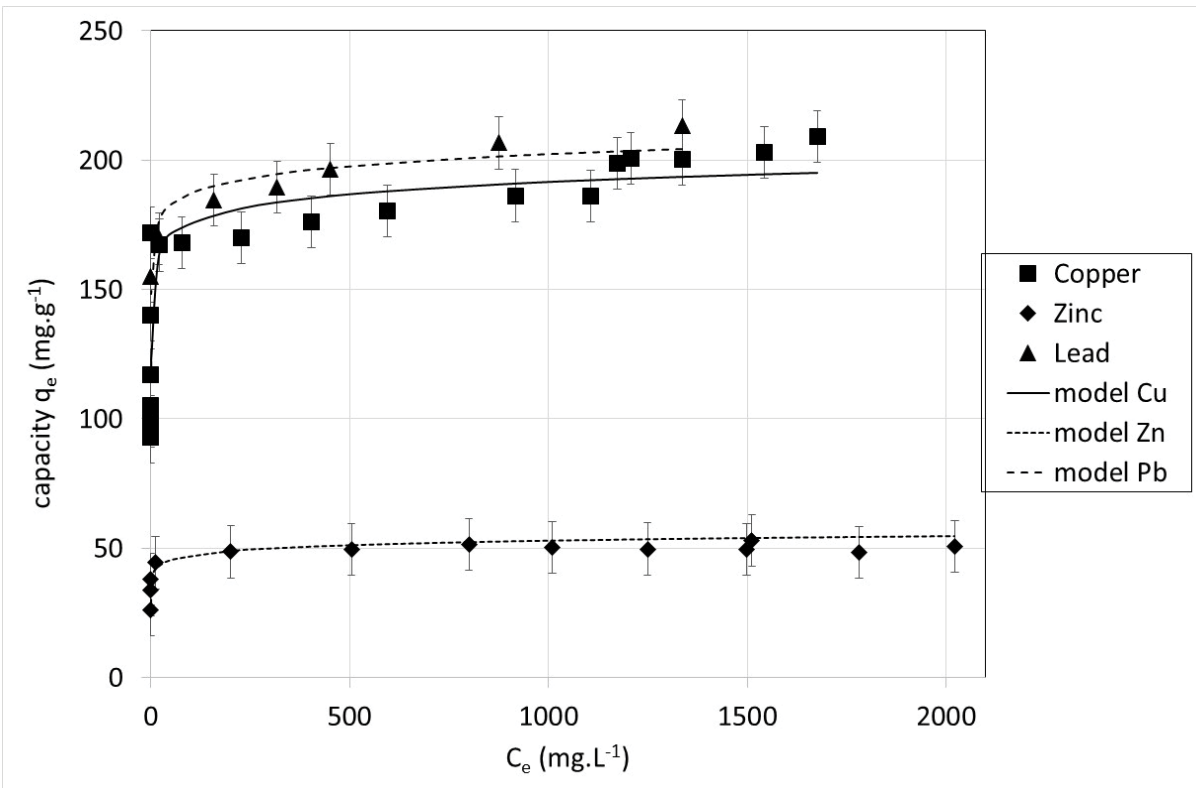

Figure 5: Experimental and modeled isotherms obtained for copper, zinc and lead ions on CSH at $22^{\circ} \mathrm{C}$.

Table 3: Maximum sorption capacities (mg.g ${ }^{-1}$ ) for CSH (this study) and other adsorbents.

\begin{tabular}{|c|c|c|c|c|}
\hline Material & Cu capacity (mg.g ${ }^{-1}$ ) & $\mathrm{Pb}$ capacity (mg. $\mathrm{g}^{-1}$ ) & Zn capacity (mg.g ${ }^{-1}$ ) & Ref. \\
\hline Zeolite (Clinoptilolite) & 25.7 & 290.1 & 17.5 & {$[23]$} \\
\hline Zeolite (Egyptian Kaoline ) & 43.8 & 213.4 & 41.2 & {$[31]$} \\
\hline Zeolite (Chabasite) & 5.1 & 6.0 & 5.5 & [32] \\
\hline Zeolite X & 109 & 549 & & [32] \\
\hline Zeolite 13X & 136 & & & [32] \\
\hline Activated carbon & 7.7 & 19.3 & 3.5 & {$[24]$} \\
\hline Clays & 54.1 & 239 & 250 & [33] \\
\hline $\mathrm{CSH} /$ Chitosan & 425 & 796 & 400 & {$[24]$} \\
\hline $\mathrm{CSH}$ & 680 & & 252 & {$[26]$} \\
\hline $\mathrm{CSH}$ & $209 \pm 21$ & $213 \pm 22$ & $53 \pm 6$ & This study \\
\hline
\end{tabular}

order are higher than the RMSE for the pseudo-second order. Moreover, the determination coefficient $R^{2}$ are closer to 1 for the pseudo-second order model, meaning that it better represents experimental data. The pseudo-first order kinetics model is particularly adapted for fast sorption processes [29] which are not the case in this study where the sorption is quite slow and then better fitted by pseudo-second order kinetics model. Bonilla-Petriciolet, et al. [29] stated that the pseudo-second order kinetics model has been successfully applied to the adsorption of metal ions from aqueous solutions.

Finally, kinetics measurements showed that the mechanism involved in the metal capture is ion exchange with a release of calcium from the $\mathrm{CSH}$. As for many liquid systems, the equilibrium is reached after long times even if a large decrease of the concentrations is observed after few hours for zinc, lead and copper in solution. A pseudo-second order kinetics allows the modelling of the global phenomenon probably controlled by the reaction step.
Isotherms: Following the described procedure, sorption isotherms representing the equilibrium capacity after 10 days $\left(q_{\mathrm{e}}\right)$ versus the equilibrium concentration in the liquid phase $\left(C_{\mathrm{e}}\right)$ were obtained with single metal solutions at $22^{\circ} \mathrm{C}$ (Figure 5).

The obtained isotherms are all of type I according to the IUPAC classification [30]. It is important to note that the isotherms are extremely steep: Maximum sorption capacities are reached for very low concentrations. This is compatible with ion exchange mechanism while the exchanger is not close to its maximum exchange capacity (corresponding in our case to a metal deficit compared to the calcium availability). The obtained results show that the maximal weight sorption capacities were as follows: $\mathrm{Pb}$ (II) $>\mathrm{Cu}$ (II) $>>\mathrm{Zn}(\mathrm{II})$. The maximum experimental sorption capacity attained $213 \mathrm{mg} \cdot \mathrm{g}^{-1}$ for $\mathrm{Pb}(\mathrm{II}), 209 \mathrm{mg} \cdot \mathrm{g}^{-1}$ for $\mathrm{Cu}(\mathrm{II})$ and $53 \mathrm{mg} \cdot \mathrm{g}^{-1}$ for $\mathrm{Zn}(\mathrm{II})$. These weight capacities were compared with previously reported data for several adsorbents (Table 3) showing that the maximum sorption capacities of the studied CSH are often greater. Unsurprisingly, activated carbons show poor performance for 
Citation: Brogat M, Pontvianne S, Sigot L, Vallières C (2021) Removal of Heavy Metal Cations (Copper, Lead, Zinc) from Water Runoff by Calcium Silicate Hydrate: Effect of the Co-Ion and Competition of lons in Ternary Mixtures. Adv Environ Stud 5(1):404-415

metal ion removal whereas zeolites and clays have high capacities. Lead weight capacity seems to be higher than that of copper and zinc in almost all the studies.

When speaking in molar sorption capacities the order is $\mathrm{Cu}(\mathrm{II})>\mathrm{Pb}(\mathrm{II})>\mathrm{Zn}(\mathrm{II})$ and the maximum experimental capacities are $3.29 \mathrm{mmol} . \mathrm{g}^{-1}$ for $\mathrm{Cu}(\mathrm{II}), 1.03 \mathrm{mmol} . \mathrm{g}^{-1}$ for $\mathrm{Pb}(\mathrm{II})$ and $0.81 \mathrm{mmol} . \mathrm{g}^{-1} \mathrm{for} \mathrm{Zn}(\mathrm{II})$. The maximum quantity of metal that is retained by the CSH can be linked to the amount of exchangeable calcium present in the solid. Thus, the amounts retained are more important in [26] for all metals as the amount of calcium is. Calculations showed that only $62 \%, 19 \%$ and $15 \%$ of the calcium available in the CSH is exchanged respectively for copper, lead and zinc. As in ion exchange resins [34,35], the differences between metallic ion could be correlated with the hydrated ionic radius and electronegativity of metallic species (Table 4). The retained amount tends to increase as the hydrated ionic radius decreases because smaller species make the solid structure swell less, so the work to go to equilibrium is lower. Furthermore, the greater the electronegativity of the species, the more significant the ion exchange $[34,35]$.

Experimental isotherms are commonly represented by isotherm models, among which Langmuir model is one of the most used to model sorption equilibrium. The Langmuir theory assumes a limited and constant number of sites for exchange and that the exchange is reversible. To establish the mathematical expression of the isotherm, Langmuir admits that at all times, there is a dynamic balance between the speeds of fixation and desorption. In this case, it is a simple application of the mass action law leading to the Langmuir thermodynamic equilibrium constant defined as

$$
b\left(\text { L.mg }^{-1}\right)=\frac{[\text { fixed species }]_{e q}}{\left[M^{2+}\right]_{e q} \cdot[\text { vacant site }]_{e q}} .
$$

As the number of sites is constant, they are either vacant or containing a fixed species. Defining $q_{\mathrm{e}}$ as the amount of retained metal at equilibrium $\left(\mathrm{mg} \cdot \mathrm{g}^{-1}\right)$ and $q_{\max }\left(\mathrm{mg} \cdot \mathrm{g}^{-1}\right)$ as the maximum amount of retained metal, the quantity of vacant

Table 4: Hydrated ionic radius and electronegativity of metal species (reported from [31]).

\begin{tabular}{|l|l|l|}
\hline Metal & Hydrated ionic radius (̊) & Electronegativity (kJ.mol ${ }^{-1}$ ) \\
\hline $\mathrm{Pb}$ & 4.01 & 1.8 \\
\hline $\mathrm{Cu}$ & 4.19 & 1.9 \\
\hline $\mathrm{Zn}$ & 4.30 & 1.6 \\
\hline
\end{tabular}

Table 5: Langmuir-Freundlich parameters for the sorption of single metal ions on $\mathrm{CSH}$ at $22^{\circ} \mathrm{C}$.

\begin{tabular}{|c|c|c|c|}
\hline & $\mathrm{Cu}$ & $\mathrm{Zn}$ & $\mathrm{Pb}$ \\
\hline $\mathrm{q}_{\max }\left(m g \cdot \mathrm{g}^{-1}\right)$ & 356 & 111 & 489 \\
\hline b $\left(\mathrm{L} . \mathrm{mg}^{-1}\right)$ & $710^{-3}$ & $3.410^{-4}$ & $2.210^{-6}$ \\
\hline n (-) & 12.90 & 11.10 & 17.53 \\
\hline RMSE (mg. $\left.g^{-1}\right)$ & 16.06 & 4.62 & 6.07 \\
\hline$R^{2}$ & 0.81 & 0.96 & 0.99 \\
\hline
\end{tabular}

sites is equal to $q_{\max }-q_{e} \cdot C_{e}$ is the metal concentration at equilibrium in solution (mg. $\left.\mathrm{L}^{-1}\right)$. With these definitions, the Langmuir equation is expressed as:

$$
q_{e}=\frac{q_{\max } b C_{e}}{1+b C_{e}}
$$

Langmuir model assumes that the surface is homogeneous in terms of sorption energy, the sorption is localized and each site can accommodate only one molecule. In the case of $\mathrm{CSH}$, the last two assumptions seem appropriate but the first one could be far from the experimental system. To take into account the heterogeneity of the sorption, the Langmuir-Freundlich model was developed (eq. 8).

$$
q_{e}=q_{\max } \frac{\left(b C_{e}\right)^{1 / n}}{1+\left(b C_{e}\right)^{1 / n}}
$$

Where $n(-)$ represents the surface heterogeneity. Once again, Langmuir-Freundlich parameters were determined by adjusting equation8to experimental values minimizing the RMSE value using Excel solver. The obtained parameters for each metal are collected in Table 5. All the determination coefficient $\mathrm{R}^{2}$ are superior to 0.8 signifying that the Langmuir-Freundlich model represents properly the experimental data. One can note that $\mathrm{n}$ parameters are really higher than 1 for the three metals, which confirms that the surface of $\mathrm{CSH}$ cannot be assimilated to a homogeneous one.

\section{Influence of the co-ion}

Metal ions in solution are accompanied by an equivalent opposite charge amount of so-called co-ions. Sorption isotherms were also determined at $22{ }^{\circ} \mathrm{C}$ for $\mathrm{Cu}$ (II) and $\mathrm{Zn}$ (II) using solutions prepared from sulfate salts in place of nitrate (Figure 6). As predicted by the literature [31], ion exchange is favored by co-ions of higher valence. This is very impacting for copper whose capacity is doubled when associated with sulfate $\left(\mathrm{SO}_{4}{ }^{2-}\right)$ instead of nitrate $\left(\mathrm{NO}_{3}{ }^{-}\right)$. The effect of the coion is significantly weaker for $\mathrm{Zn}(\mathrm{II})$.

Another point to note is the decrease of the concentration of sulfate anions in the solution as CSH mass increases whereas the concentration of nitrate anions remains constant for both $\mathrm{Zn}(\mathrm{II})$ and $\mathrm{Cu}(\mathrm{II})$ (Figure 7). As the solution stays electroneutral, the decrease of sulfate ion concentration is probably due to calcium sulfate precipitation. Indeed, this observation can be linked to the poor solubility of calcium sulfate compared to calcium nitrate (respectively about $2.1 \mathrm{~g} \cdot \mathrm{L}^{-1}$ and 1212 g. $\mathrm{L}^{-1}$ at $20^{\circ} \mathrm{C}$ ). A part of sulfate ions precipitates with calcium ion excess released by ion exchange with metal cations $\left(\mathrm{Cu}^{2+}\right.$ or $\mathrm{Zn}^{2+}$ ) leading to a joint reduction of the metal and sulfate ions. Considering that the molar amount of $\mathrm{Ca}^{2+}$ released is equal to the amount of $\mathrm{M}^{2+}$ captured and knowing the calcium sulfate solubility, it is possible to calculate the quantity of sulfate precipitating. Thus, the theoretical remaining soluble sulfate concentration $\left(C_{\mathrm{e}}\right)$ corresponds to $33 \%$ of the initial sulfate concentration $\left(C_{0}\right)$ that is consistent with the value of approximately $36 \%$ reported on Figure 7 for high CSH masses whatever the metal. 

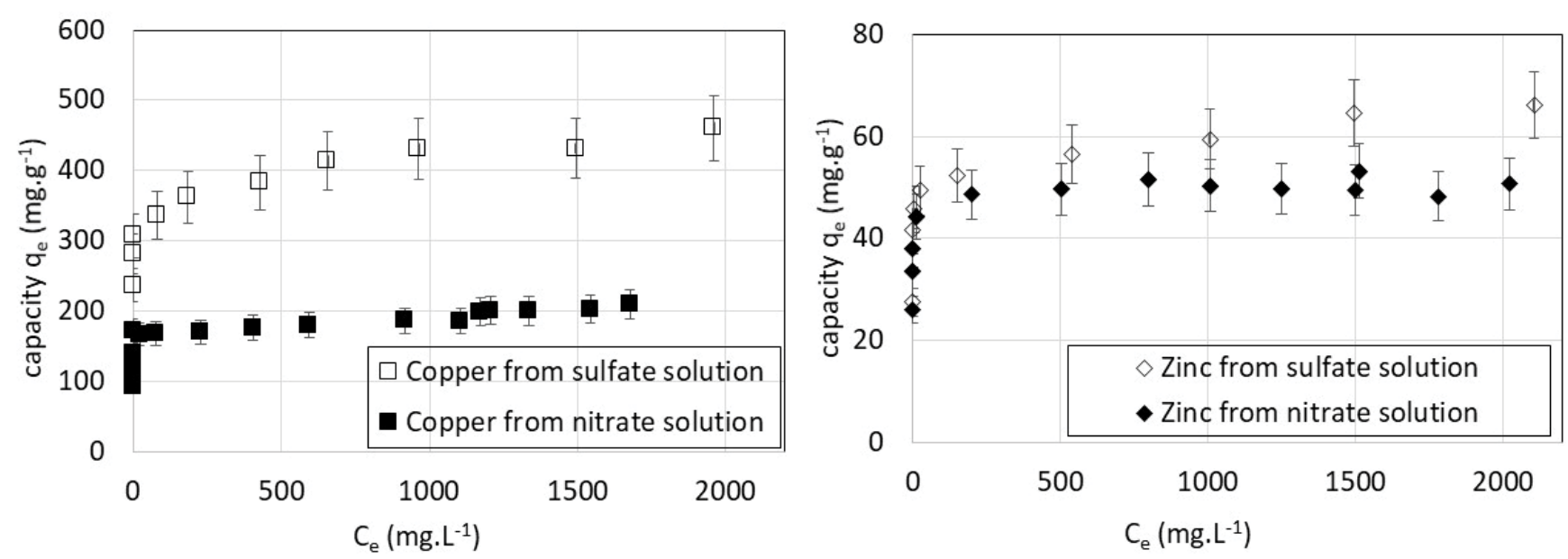

Figure 6: Experimental isotherms for the sorption of copper (left) and zinc (right) in both single metal solutions from sulfate and nitrate $\left(\mathrm{T}=22^{\circ} \mathrm{C}, \mathrm{C}_{0}=3000 \mathrm{mg} \cdot \mathrm{L}^{-1}, \mathrm{~V}=200 \mathrm{~mL}\right.$ ).
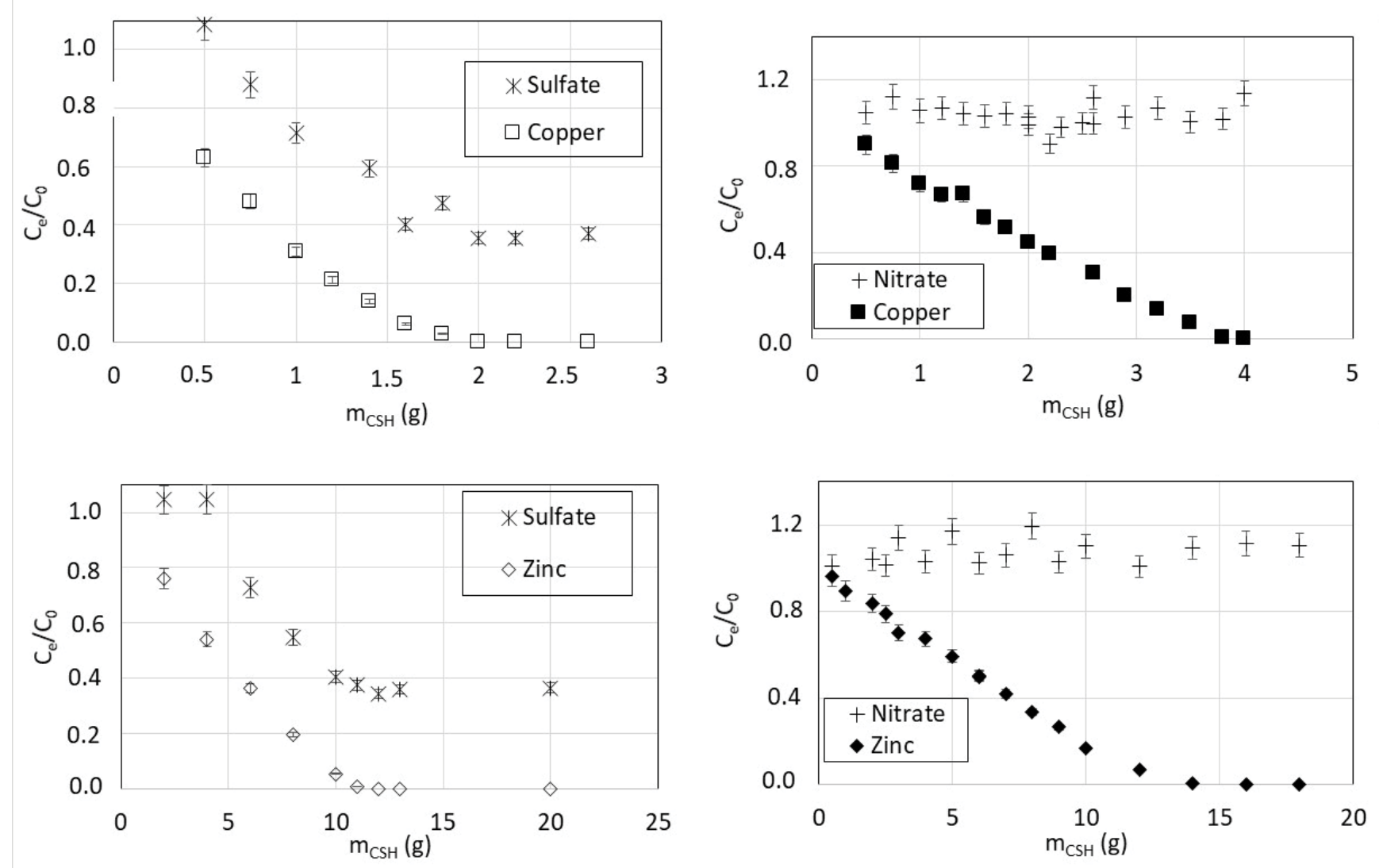

Figure 7: Experimental reduction of the concentrations of the metal and co-ion for the sorption of copper (above) and zinc (below) in both single metal solutions from sulfate (left) and nitrate (right) as a function of $\mathrm{CSH}$ mass introduced in the solution. $\left(\mathrm{T}=22^{\circ} \mathrm{C}, \mathrm{C}_{0}=3000\right.$ $\mathrm{mg} \cdot \mathrm{L}^{-1}, \mathrm{~V}=200 \mathrm{~mL}$ ).

\section{Influence of the presence of several metal ions}

According to Mishra, et al. [36] and Jha, et al. [37], the presence of other cations in the solution results in the reduction of the maximum sorption capacity for each metal compared to that obtained in single metal solutions.

In order to investigate the influence of the presence of competing heavy metal ions on the individual sorption of $\mathrm{Cu}(\mathrm{II}), \mathrm{Zn}(\mathrm{II})$ and $\mathrm{Pb}$ (II) by $\mathrm{CSH}$, experiments were carried out with a solution containing a mixture of the three metals prepared from nitrate salts. The initial concentration of each metal was $3000 \mathrm{mg} . \mathrm{L}^{-1}$ and the experiment was conducted for three masses of $\mathrm{CSH}$, namely $2.5 \mathrm{~g}, 6 \mathrm{~g}$ and $12.5 \mathrm{~g}$. Figure 8 shows the sorption kinetics of each heavy metal present in 

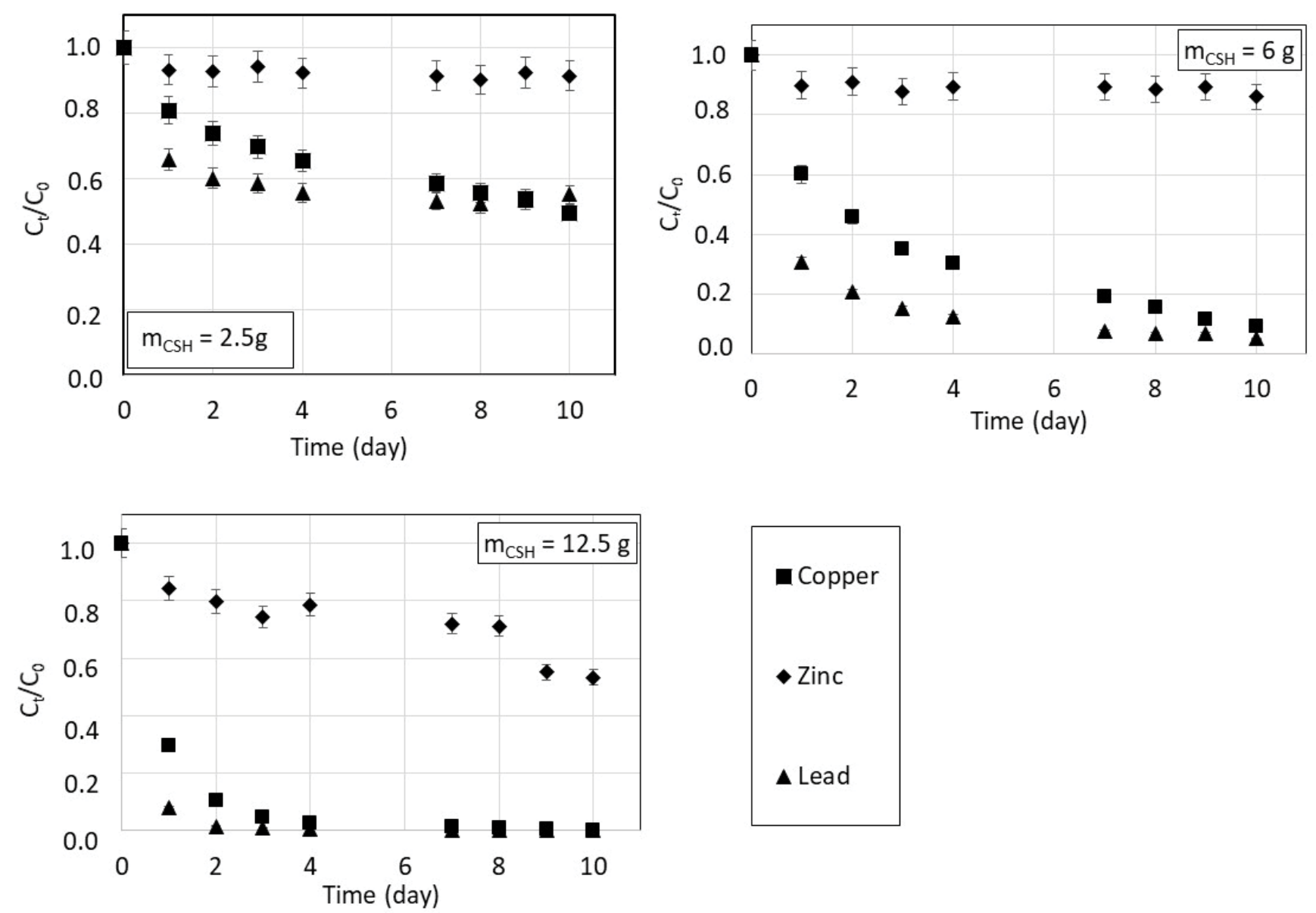

Figure 8: Kinetics for copper, zinc and lead removal in ternary solutions using $\mathrm{CSH}\left(\mathrm{T}=22^{\circ} \mathrm{C}, \mathrm{C}_{0}=3000 \mathrm{mg} \cdot \mathrm{L}^{-1}\right.$ for each metal, $\mathrm{V}=200 \mathrm{~mL}$ ).

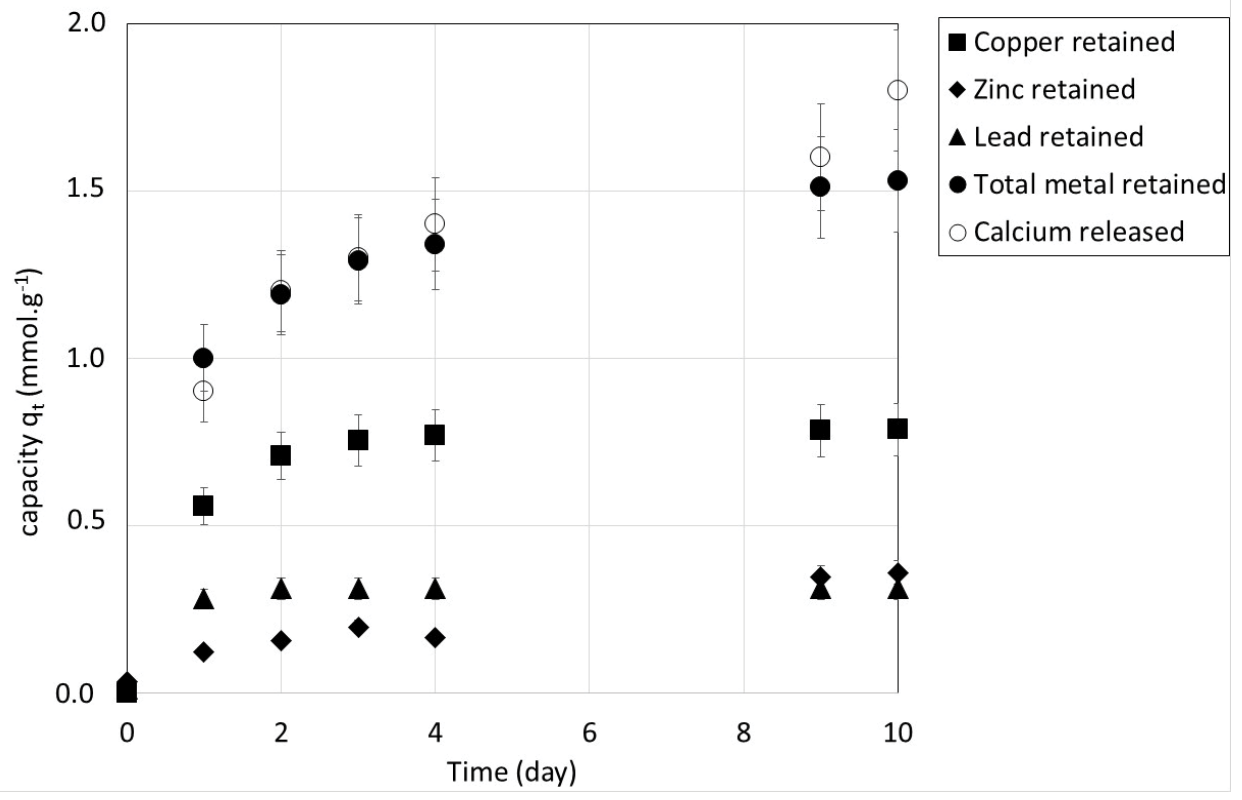

Figure 9: Amount of total metal (copper, zinc and lead) retained and amount of calcium released from CSH $\left(\mathrm{T}=22^{\circ} \mathrm{C}, \mathrm{C}_{0}=3000 \mathrm{mg} . \mathrm{L}^{-1}\right.$ for each metal, $\mathrm{m}_{\mathrm{CSH}}=12.5 \mathrm{~g}$ ).

the mixture. For each ionic species, the greater the mass of $\mathrm{CSH}$, the more rapid and better the removal from the solu- tion. A comparison of Figure 1 and Figure 8 shows that the sorbed quantities of each ion are lower when they are in 
Citation: Brogat M, Pontvianne S, Sigot L, Vallières C (2021) Removal of Heavy Metal Cations (Copper, Lead, Zinc) from Water Runoff by Calcium Silicate Hydrate: Effect of the Co-Ion and Competition of Ions in Ternary Mixtures. Adv Environ Stud 5(1):404-415

mixture revealing a competitive effect. Moreover, the experiments showed that zinc kinetics is much lower. This is probably due to its lower mobility. To be sorbed, zinc ions must reach the least available calcium sites or wait for copper and lead concentrations to be very low. This kinetics selectivity has an important impact on zinc removal which is the most affected by the presence of other metals in solution. For all experimental conditions, one can consider that after 10 days, a pseudo equilibrium is reached.

In the case of a mixture, Figure 9 shows the amount of total metal (copper, zinc and lead) retained on the $\mathrm{CSH}$ and the amount of calcium released to the solution during a kinetics experiment. Once more, the correspondence of the uptake of total metal from the solution with the release of $\mathrm{Ca}$ (II) by $\mathrm{CSH}$ confirms the presence of ion exchange mechanisms in the metal sorption process.

The sorption isotherms obtained with ternary metal solutions using $\mathrm{CSH}$ are shown in Figure 10. This figure represents the quantity of a metal sorbed at the equilibrium versus its concentration at the equilibrium in the liquid phase in the presence of other metal ions. The comparison of Figure 5 and Figure 10 highlights that the sorption capacity at equilibrium for each metal ion is significantly reduced in ternary solution.

Maximal sorption capacities of each metal are reported in Table 6. The proportion of metal retained in mixture compared to single metal solutions decreased as follows: $\mathrm{Zn}(\mathrm{II})>$ $\mathrm{Pb}(\mathrm{II})>\mathrm{Cu}(\mathrm{II})$.

The elementary analysis of the $\mathrm{CSH}$ material showed that there is approximately $5 \mathrm{mmol}$ of calcium per gram of solid. The experiments carried out with single metal ions make it possible to exchange $3.3 \mathrm{mmol} . \mathrm{g}^{-1}$ with copper. In a competitive ternary mixture, Table 6 shows that the total amount of calcium exchanged is similar $\left(3.1 \mathrm{mmol}^{-1}\right)$. Therefore, the amount of each retained metal decreases but the total capacity remains constant corresponding to approximately $60 \%$ of the calcium available in the $\mathrm{CSH}$.

\section{Conclusion}

This study showed that metal removal from aqueous solutions by $\mathrm{CSH}$ is performed by ion exchange with calcium from

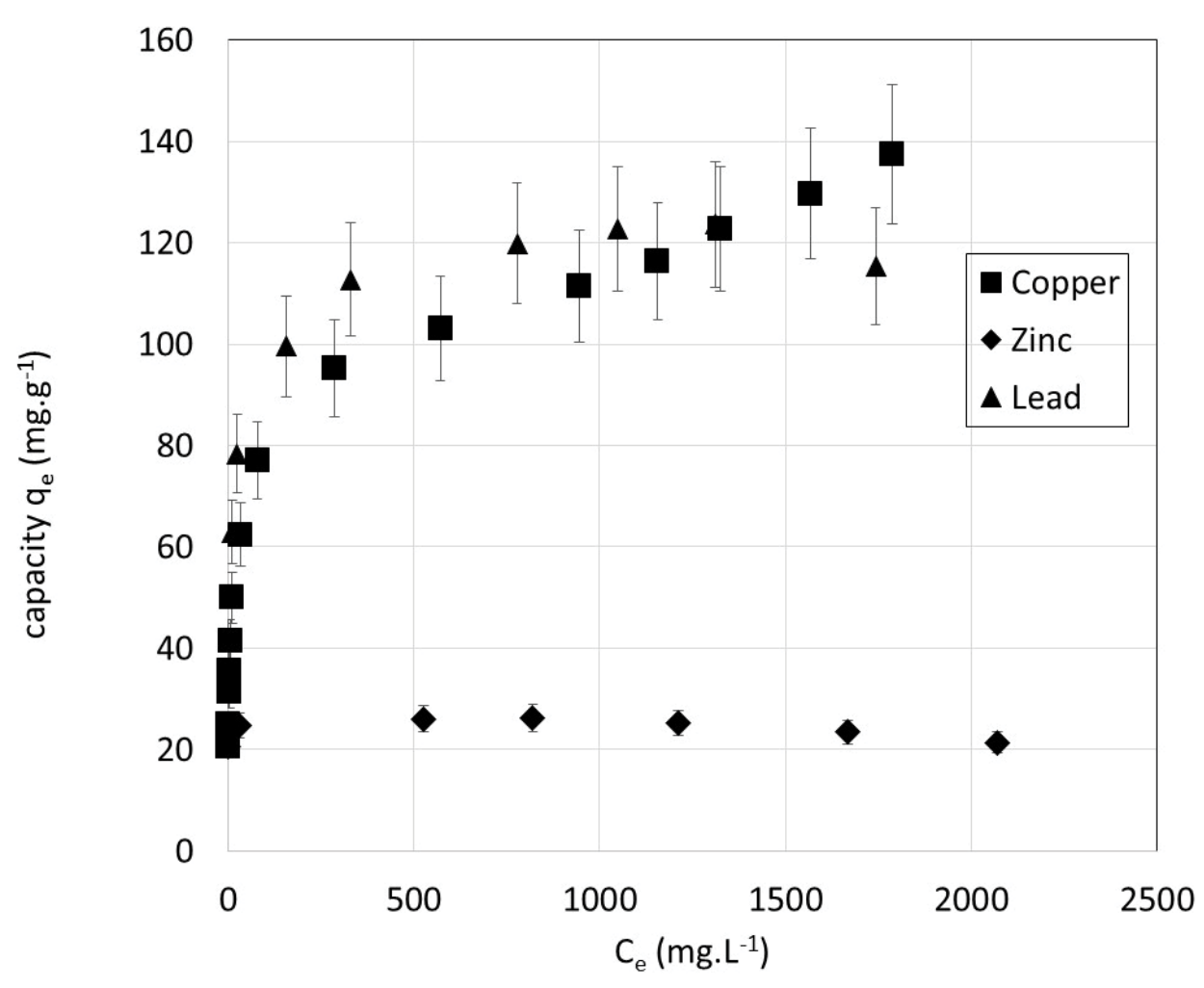

Figure 10: Experimental isotherms for the sorption of copper, zinc and lead in ternary solutions on CSH at $22^{\circ} \mathrm{C}$.

Table 6: Maximal sorption capacities (single metal and ternary solutions) at $22^{\circ} \mathrm{C}$.

\begin{tabular}{|c|c|c|c|c|c|}
\hline \multirow[t]{2}{*}{ Metal } & \multicolumn{2}{|c|}{ Single metal solution } & \multicolumn{2}{|c|}{ Ternary solution } & \multirow[t]{2}{*}{ Decrease (\%) } \\
\hline & $\mathrm{mg} \cdot \mathrm{g}^{-1}$ & mmol.g $\mathrm{g}^{-1}$ & $\mathrm{mg} \cdot \mathrm{g}^{-1}$ & mmol.g $\mathrm{g}^{-1}$ & \\
\hline $\mathrm{Pb}(\mathrm{II})$ & $213 \pm 22$ & $1.03 \pm 0.11$ & $115 \pm 12$ & $0.55 \pm 0.06$ & 46 \\
\hline $\mathrm{Cu}(\mathrm{II})$ & $209 \pm 21$ & $3.29 \pm 0.33$ & $137 \pm 14$ & $2.16 \pm 0.22$ & 34 \\
\hline $\mathrm{Zn}(\mathrm{II})$ & $53 \pm 6$ & $0.81 \pm 0.08$ & $23 \pm 3$ & $0.35 \pm 0.04$ & 56 \\
\hline Total & & & & $3.06 \pm 0.32$ & \\
\hline
\end{tabular}


Citation: Brogat M, Pontvianne S, Sigot L, Vallières C (2021) Removal of Heavy Metal Cations (Copper, Lead, Zinc) from Water Runoff by Calcium Silicate Hydrate: Effect of the Co-Ion and Competition of Ions in Ternary Mixtures. Adv Environ Stud 5(1):404-415

the material.

Whatever the metal, the transfer kinetics, properly represented by pseudo-second order kinetics model, is quite slow, even more for zinc. Even if more than $50 \%$ (between $55 \%$ and $75 \%$ ) of the removal potential is expressed during the first hours, it is necessary to wait ten days to reach the equilibrium. Therefore, for the conception and development of in-situ runoff water treatment solution, it is essential to allow enough contact time to take advantage of the whole $\mathrm{CSH}$ capacity.

The differences observed between each metal equilibrium molar capacity can be linked to their structural properties, in particular their hydrated ionic radius and electronegativity. The isotherms emphasized that the equilibrium weight capacity is higher for lead than for copper than for zinc. At saturation, about $60 \%$ maximum of the calcium available in the $\mathrm{CSH}$ is used for ion exchange. The maximum metal weight capacities obtained experimentally are comparable or even higher than those found in the literature for conventional materials such as zeolites and activated carbons, commonly used for water treatment. In terms of thermodynamics, this low cost adsorbent (whose basic composition could easily be found in industrial residues) has an interesting potential.

An important impact of the co-ions present in solution was underlined, particularly for copper whose maximal weight capacity was doubled in the presence of sulfate rather than nitrate ions of lower valence. Calcium sulfate precipitation phenomenon was also observed.

Competition phenomena were highlighted in the case of metal mixture. Even if the total retention capacity is not affected, the maximum single uptakes for each metal are reduced. Zinc removal is mainly impacted due to kinetics selectivity partly associated to its physicochemical properties.

\section{Acknowledgements}

This work was supported by the Région Lorraine in the frame of FEDER FSE Lorraine et Massif des Vosges 2014-2020 call for projects. We would like to thank the cluster Hydreos (Pôle decompétitivité Alsace-Lorraine), Jean-François Remy for his support concerning SEM micrographs and EDX spectra acquisitions, and Justine Leys for the work done during her undergraduate year.

\section{References}

1. Ali H, Khan E, Sajad MA (2013) Phytoremediation of heavy metals--concepts and applications, Chemosphere 91: 869-881.

2. The European Parliament and Council (2000) Directive 2000/60/ EC of the European Parliament and of the Council establishing a framework for community action in the field of water policy.

3. US Environmental Protection Agency (2007) Framework for metals risk assessment.

4. Ferreira M, Lau SL, Stenstrom MK (2013) Size fractionation of metals present in highway runoff: Beyond the six commonly reported species, Water Environ Res 85: 793-805.

5. Gnecco I, Berretta C, Lanza L, et al. (2005) Storm water pollution in the urban environment of Genoa, Italy, Atmos Res 77: 60-73.
6. Helmreich B, Hilliges R, Schriewer A, et al. (2010) Runoff pollutants of a highly trafficked urban road - correlation analysis and seasonal influences. Chemosphere 80: 991-997.

7. Lamprea K, Ruban V (2011) Pollutant concentrations and fluxes in both stormwater and wastewater at the outlet of two urban watersheds in Nantes (France), Urban Water Journal 8: 219-231.

8. Azimi S, Ludwig A, Thévenot DR, et al. (2003) Trace metal determination in total atmospheric deposition in rural and urban areas, Sci Total Environ 308: 247-256.

9. Maniquiz RM, Kim LH (2014) Fractionation of heavy metals in runoff and discharge of a stormwater management system and its implications for treatment. J Environ Sci 26: 1214-1222.

10. Napier F, D'Arcy B, Jefferies C (2008) A review of vehicle related metals and polycyclic aromatic hydrocarbons in the UK environment. Desalination 226: 143-150.

11. Brown JN, Peake BM (2006) Sources of heavy metals and polycyclic aromatic hydrocarbons in urban stormwater runoff. Sci Total Environ 359: 145-155.

12. Göbel P, Dierkes C, Coldewey WG (2007) Storm water runoff concentration matrix for urban areas. Journal of Contaminant Hydrology 91: 26-42.

13. Erdem E, Karapinar N, Donat R (2004) The removal of heavy metal cations by natural zeolites. J Colloid Interface Sci 280: 309-314.

14. Malamis S, Katsou E (2013) A review on zinc and nickel adsorption on natural and modified zeolite, bentonite and vermiculite: Examination of process parameters, kinetics and isotherms. J Hazard Mater 252-253: 428-461.

15. Nguyen TC, Loganathan $P$, Nguyen TV, et al. (2015) Simultaneous adsorption of $\mathrm{Cd}, \mathrm{Cr}, \mathrm{Cu}, \mathrm{Pb}$, and $\mathrm{Zn}$ by an iron-coated Australian zeolite in batch and fixed-bed column studies. Chemical Engineering Journal 270: 393-404.

16. Rafati M, Khorasani N, Moattar F, et al. (2011) Phytoremediation potential of populus alba and morus alba for cadmium, chromuim and nickel absorption from polluted soil. IInt J Environ Res 5: 961-970.

17. Zhang L, Zeng $Y$, Cheng $Z$ (2016) Removal of heavy metal ions using chitosan and modified chitosan: A review. Journal of Molecular Liquids 214: 175-191.

18. Huang $Y$, Wu D, Wang $X$, et al. (2016) Removal of heavy metals from water using polyvinylamine by polymer-enhanced ultrafiltration and flocculation. Separation and Purification Technology 158: 124-136.

19. Tortora F, Innocenzi V, Prisciandaro M, et al. (2016) Heavy metal removal from liquid wastes by using micellar-enhanced ultrafiltration. Water, Air, \& Soil Pollution 227.

20. Lin L, Xu X, Papelis C, et al. (2014) Sorption of metals and metalloids from reverse osmosis concentrate on drinking water treatment solids. Separation and Purification Technology 134: 37-45.

21. Ghaedi M, Biyareh MN, Kokhdan SN, et al. (2012) Comparison of the efficiency of palladium and silver nanoparticles loaded on activated carbon and zinc oxide nanorods loaded on activated carbon as new adsorbents for removal of Congo red from aqueous solution: Kinetic and isotherm study. Materials Science and Engineering: C 32: 725-734.

22. Ostroski IC, Barros MASD, Silva EA, et al. (2009) A comparative study for the ion exchange of Fe(III) and Zn(II) on zeolite NaY. J Hazard Mater 161: 1404-1412. 
Citation: Brogat M, Pontvianne S, Sigot L, Vallières C (2021) Removal of Heavy Metal Cations (Copper, Lead, Zinc) from Water Runoff by Calcium Silicate Hydrate: Effect of the Co-Ion and Competition of Ions in Ternary Mixtures. Adv Environ Stud 5(1):404-415

23. Wang S, Peng Y (2010) Natural zeolites as effective adsorbents in water and wastewater treatment. Chemical Engineering Journal 156: 11-24.

24. Zhao J, Zhu YJ, Wu J, et al. (2014) Chitosan-coated mesoporous microspheres of calcium silicate hydrate: Environmentally friendly synthesis and application as a highly efficient adsorbent for heavy metal ions. Journal of Colloid and Interface Science 418: $208-215$

25. Chen $Q$, Hills CD, Yuan M, et al. (2008) Characterization of carbonated tricalcium silicate and its sorption capacity for heavy metals: A micron-scale composite adsorbent of active silicate gel and calcite. J Hazard Mater 153: 775-783.

26. Ma J, Qin G, Zhang Y, et al. (2018) Heavy metal removal from aqueous solutions by calcium silicate powder from waste coal fly-ash. Journal of Cleaner Production 182: 776-782.

27. Gupta A, Balomajumder C (2015) Simultaneous adsorption of $\mathrm{Cr}(\mathrm{VI})$ and phenol onto tea waste biomass from binary mixture: Multicomponent adsorption, thermodynamic and kinetic study. Journal of Environmental Chemical Engineering 3: 785-796.

28. Ullah R, Nadeem M, Iqbal Q, et al. (2013) Biosorption of chromium onto native and immobilized sugarcane bagasse waste biomass. Ecological Engineering 60: 99-107.

29. Bonilla P, Mendoza CDI, Reynel AHE (2017) Adorption processes for water treatment purification. Springer International Publishing.
30. Rouquerol F, Rouquerol J, Sing KSW, et al. (2014) Adsorption by powders and porous solids. ( $\left.2^{\text {nd }} \mathrm{edn}\right)$, Academic Press, Oxford.

31. Ibrahim HS, Jamil TS, Hegazy EZ (2010) Application of zeolite prepared from Egyptian kaolin for the removal of heavy metals: II. Isotherm models. Journal of Hazardous Materials 182: 842-847.

32. Ziyath AM, Mahbub P, Goonetilleke A, et al. (2011) Influence of physical and chemical parameters on the treatment of heavy metals in polluted stormwater using zeolite-A review. Journal of Water Resource and Protection 3: 758.

33. Uddin MK (2017) A review on the adsorption of heavy metals by clay minerals, with special focus on the past decade. Chemical Engineering Journal 308: 438-462.

34. LeVan M, Carta G, Yon C (1997) Section 16. Adsorption and ion exchange. In: Green DW (edn), Perry's chemical engineers' handbook. ( $7^{\text {th }}$ edn), McGraw-Hill, New York, 1997.

35. F Helfferich. Ion exchange, Dover Publication, INC, New York.

36. Mishra PC, Patel RK (2009) Removal of lead and zinc ions from water by low cost adsorbents. Journal of Hazardous Materials 168: 319-325.

37. Jha VK, Matsuda M, Miyake M (2008) Sorption properties of the activated carbon-zeolite composite prepared from coal fly ash for $\mathrm{Ni2}+, \mathrm{Cu} 2+, \mathrm{Cd} 2+$ and $\mathrm{Pb} 2+$. Journal of Hazardous Materials 160: $148-153$. 